\title{
Lost in Translation: an Experiment with Memes for Research Translation in Australian Early Childhood Education and Care (ECEC) Contexts
}

\author{
Research Translation
}

\author{
Fiona Westbrook | ORCID: 00oo-00o2-0744-6721 \\ School of Education (Early Childhood), RMIT University, Melbourne, Australia \\ fiona.westbrooko@gmail.com
}

Elise Hunkin | ORCID: oooo-ooo1-639o-8233

School of Education (Early Childhood), RMIT University, Melbourne, Australia elise.hunkin@rmit.edu.au

Jayne White | ORCID: oooo-0oo2-1467-8125

Education, Health \& Human Development, University of Canterbury, Christchurch, New Zealand

Professor II, KINDknow Research Centre, Western Norway University of Applied Sciences, Norway

jayne.white@canterbury.ac.nz

\begin{abstract}
Early transitions are on the rise across global and national contexts. However, resources informing teachers and families about best practices concerning infants, especially infant transitions from home to early childhood settings, are almost non-existent. In this article, the authors share the outcomes of an experiment that translated research from an International Study of the Social and Emotional Experiences of Early Transitions (ISSEET) project into a range of visual resources for this audience. They created a suite of video, infographic and meme visual resources that outlined 'what works' for quality early transitions and sought end-user feedback around their utility. While the feedback was positive overall concerning infographics and videos, end-users expressed strong negative responses to the use of memes. In the article that follows, the authors explore why it might be so. They draw on the Bakhtinian concept of genre. With its form, content and strategic orientation, they translate and interpret
\end{abstract}


the meaning ascribed to the memes. They argue that the complex humour and cultural memory that sit behind memes grants them unique translation status. Reflecting on the responses, the authors consider pathways for memes as impactful research translation for end-users - in this case, early years teachers.

\section{Keywords}

research translation - meme - research translation - infant transitions - ECEC professionalism - neoliberalism

\section{1 \\ Introduction}

Visual resources that translate research findings into accessible messages for end-users concerning pedagogies are increasing, but not always in holistic ways. The resources that exist do not evenly cater to all aspects of education or ECEC. For instance, whilst the transition to primary school has a wealth of research translated into accessible resources, those for infant transitions from home into early years services are severely limited. Meanwhile, a growing number of increasingly younger children attending childcare in many parts of the world (White, Marwick, Amorim, Karagiannidou, \& Herold, in press; White, 2017) emphasises the need for research-informed infant transition resources. Although there are numerous resources targeting experiences in the first 100 days (Bupa, 2017; Te Rūnanga Ngāi Tahu, 2018; UNICEF, 2018), these tend to focus on family contexts, developmental concerns and discrete aspects of infant development such as nutrition, language development, attachment and so on (Adams \& Parlakian, 2010; Beben \& McCormilla, 2012; Miller, 2005).

Our investigation discovered that what resources exist for infant transitions are often text-heavy, having little visual orientation. Beyond the educational sector, research has emphasised that resource impact directly correlates to visual appeal (Djamasbi et al., 2010; Lindgaard et al., 2011). With the earliest transitions shown to be complex and highly emotional for infants, families and educators (White et al., 2020), impactful resources are therefore sorely needed. Furthermore, infant transitions are heavily affected by adult community members, perceptions and practices (White et al., in press), stressing the importance of research-informed, supportive and visually appealing resources for this demographic. To address this gap, we, the researchers from the Melbourne arm of the International Study of Social 
Emotional Early Transitions (ISSEET), undertook a research translation project. Our intent was to harness resources that shared our findings in ways that may result in high quality and relevant outcomes for transitioning infants, teachers and families. To do so, we translated key messages from the data into informal, easy to understand, contemporary visual genres that included videos, infographics and memes.

In this article, we focus on the meme products that were generated through the Bakhtinian concept of genre. Bakhtin (1986) described this as a "speech plan or speech will, which determines the entire utterance, its length and boundaries" (p. 77). Analysing each meme's genre as a visual resource invites interpretations of the intent of their production and their sector reception. Exploring the relationship between form (of language or trope) and content (intended and received meaning) provides a portal to understanding not only the memes' intended messages but their reception. Drawing on feedback surveys from early childhood education and care (ECEC) community members we, therefore, explore the sector's perceptions of the memes alongside our intentions. We speculate on the requisite knowledges that underpin a meme's efficacy as a translation genre for ECEC community members, as well as their potentialities moving forward.

\subsection{Background}

ISSEET is a global research collaboration investigating the social and emotional experiences of infants, families and educators across six countries (see https://www.earlytransitions.com): Australia, New Zealand, United States of America, Finland, Brazil, and Scotland. The project was established six years ago in response to the increasing number of infants entering ECEC at an early age, reflecting a global economic trend. Key issues surrounding infants include their positioning by policy as vulnerable, incomplete beings or "beings-in-waiting" (Peters et al., 2020, p. 3). This contributes to a lack of understanding and information about their transition experiences. A longitudinal study, the ISSEET countries collected interviews, as well as observational and video data of when the infant first transitions from home to an early childhood context, then at every transition thereafter, up to and including the transition to school (see White et al., 2020). Other typical early transitions include the change from one early childhood service to another, or from one room within a service to another room. Up to two hours of video footage was collected on the day of the transition (with an emphasis on the focus infant), and coded observational data was collected for the full duration of the infant's time at the service on that day. Informed by the growing international corpus of data, we wanted to begin disseminating key 
messages about 'what works' for quality infant transitions in novel ways. Due to ethical constraints, there were limits to sharing ISSEET data between countries and the public (Rutanen et al, 2018). This led to our interest in visual, easy to share and use digital resources for the wider intended audiences.

In phase one of the project, we conducted a review of the existing resources that revealed a lack of infant transition resources across global and local contexts. With this knowledge, we then worked with the ISSEET international team to compile, discuss and reach consensus on key messages from the data about 'what works' for quality transitions. The key messages needed to be data-informed and applicable across contexts. We also convened an Australian industry steering committee comprised of five ECEC service providers who we held regular focus groups with during the resources development. We also met with our graphic designer to discuss the type of products that would be made - type, look, style and intended usage - in an effort to ensure that the products would be fit for purpose.

Whilst there are exceptions (such as the transition to school), research informed resources for the educational sector are underrepresented (Cherney et al., 2012; Mat Roni, Merga \& Morris, 2020). Commonly research findings are trapped behind paid subscriptions and academic language (Hirschkorn \& Geelan, 2008). However, research-informed education resources have the proven potential to draw attention to and improve pedagogy and practice, as well as various systems (Levin, 2011). A key aspect for research translation's impact is to adopt language that is familiar and transparent to teachers, as well as situated and available in commonly accessed spaces (Mat Roni, Merga \& Morris, 2020). Hence, our goal in this project was to experiment with novel, informal visual genres for research translation that could be easily used and shared in and across existing online networks, such as, Facebook, Instagram and professional websites. We wanted to use visual resources because they have been shown to facilitate greater memory retention, capturing attention and assisting audience comprehension through a mixture of imagery and text (Burmark, 2002). Our resultant suite of resources includes infographics, short video clips and a series of memes (RMIT University, 2021).

Although visual methods, such as video, have gained legitimacy as a research communication tool in recent years (Pink, 2020), less is known about the efficacy of modern visual genres like memes. Memes imbue a variety of potentials since they are varied in their culture, social and political messaging (Nissenbaum \& Shifman, 2015). Originally coined as 'imitation' in 1976, memes are characterised by a behaviour or idea that contagiously and spontaneously spreads between peoples within a culture (Dawkins, 2016). Memes use digital images that are visually simplistic to convey messages about recent events, often through pop culture references. Of interest to us was the potential for 
memes to capture attention and lead audiences elsewhere, through digital links like hashtags or hyperlinks (McGrath, 2019). With the largest percentage of Australian ECEC educators aged 20-34 (Social Research Centre, 2017), there is an opportunity for researchers to leverage memes as an informal dissemination strategy for this audience.

For digital natives (often Generations Y and Z), memes can be primary information sources of global and national events (Laineste \& Voolaid, 2017), leading Nagle (2017) to describe social media as the birthplace of young people's political opinions. Saturated in memes, social media and its dialogues have risen from obscurity to mainstream languages and political sensibilities (Nagle, 2017). They have become an "increasingly prevalent means of communication in online spaces", influencing dispositions and attitudes through a participatory culture (Kearney, 2019, p. 82). Memes are typically humorous and satirical, using this genre for critical reflection in similar, albeit nuanced, ways to political cartoons in traditional press (Yus, 2018). Due to this humorous intentionality, memes are multi-layered and complex in messaging (Laineste \& Voolaid, 2017). Their complexity can build over time as the meme is shared, altered and changed in a layering of narratives (Laineste \& Voolaid, 2017). The commentary of 'in-jokes' is a key feature of memes, requiring the audience to have an awareness of the mood or event that underpins the imagery and its application, which can exclude some populations from the messaging (Wiggins, 2019). Wiggins (2019) thus defines memes as an "ideological practice" (p. xv) because they embody critique of a person or broader cultural, political, social or economic phenomenon. Memes are thus infectious notions and events that are replicated within participatory communities into "catchy" propagated ideas, containing cultural instructions or mental representation (Yus, 2018).

As an education research translation tool, memes can offer the unique capacity to capture moods and current events in a responsive way that establishes a community of ideation and participation (Moody-Ramirez \& Church, 2019). Seeing the possibilities in this space, Buchanan and Newman (2019) collaborated with Australian secondary school teachers to create memes. These multimodal dialogues gave voice to teachers' experiences that Buchanan and Newman (2019) suggest may otherwise have gone unheard. Teachers' experiences of policy reform fatigue and comical parodies of the overworked and burdened teacher in situ with a constantly shifting political landscape featured in their co-creations. Meme research translation in education can therefore give teachers a voice to express their feelings of disempowerment (Laineste \& Voolaid, 2017), enabling them to become more political by speaking back to "political discourse" (Kulkarni, 2017). Our deployment of memes as a research translation dissemination strategy is different again, walking the fine line between internet spam - unsolicited attention grabbing "to extract value" 
(Brunton, 2018, p. 566) from the audience (the latter we are not doing) - and using humorous, critical commentary to create spaces for solidarity. Although each product from the suite would be shared directly via social media outlets, our intention was that the memes would complement as a secondary dissemination strategy that leads end-users to the products (McGrath, 2019), which is sometimes called 'linkbait'.

Mikhail Bakhtin's (1986) concept of genre provides a unique site for investigation that invites consideration of the relationship between both the intentions and receptions of specific language forms (in this case, memes). By unpacking the reasons behind our selection of the memes in juxtaposition with the end-users' responses to them, we are able to contemplate the significance behind these interactions. According to White (2017), Bakhtinian genre forms an equation that reveals implicit and explicit orientations within dialogue (p. 74):

form + content $=$ strategic orientation

The form in this research encompasses memes as a mode of research translation, paying attention to the specific imagery and wording used within the memes, and their location in social media. Content refers to the meanings that are ascribed to these by the receiver. This translation considers the social orientation that underpinned their production. When the form and content are considered together as a deliberate elements, they reveal the strategic orientation of both researcher as creators of the memes and respondents who receive the messages (intended or otherwise). Such orientations can differ between the sender and receiver - as Bakhtin explains, language is not a static trope, but an event-ofbeing that plays out in its lived encounter. Our research focuses on both - our strategic orientations evidenced through the production of the memes in light of key messages from the research, and the sector responses we received.

Our strategic orientation in selecting memes were twofold. Firstly, to develop content that encouraged the audience to contemplate the lack of information available to the sector about infants' transitions. The form we selected to do so was memes with their humorous properties (Benaim, 2018). Bringing the 
Bakhtinian concept of carnivalesque to bear on genre's equation (White, 2017) we hoped our memes would spark "the bonfire which renews" (Bakhtin, 1984, p. 17) how infant transitions are approached. Memes are a well-suited genre of carnivalesque (Gradovski et al., 2019). Their form and content are often mockingly comical to offer a strategic orientation that flips officialdom for a "new outlook on the world, to realize the relative nature of all that exists, and enter a completely new order" (Bakhtin, 1984, p. 34). Therefore, our memes sought to establish provocations that might stimulate a new outlook on infant transitions and their relative nature - with adults having a high bearing on infants' transitional experiences (White et al., in press). Furthermore, as carnivalesque laughter must be participatory (Bakhtin, 1984), our selection of memes as a genre was an attempt at ironic, jovial teacher engagement about the lack of support offered to them for infant transitions. This is significant as ECEC teachers are frequently asked to meet newly imposed standards but are likely to encounter inadequate support and material, especially for under researched areas (Schwartz et al., 2019) such as infant transitions.

Secondly, our strategic orientation intended audiences to action this contemplation by following the links to access the resources (McGrath, 2019). The content of our genre called on popular, well-known meme-agery that parodied through satirical humour contexts where something was missing or amiss (Johnson, 2019, March 24): This is Fine meme (see Figure 1), Monkey Puppet meme (see Figure 2) \& Left Exit meme (see Figure 3).

Our genre in selecting these memes, is a strategic orientation that attempts to balance satirical irony and serious commentary, so as to capture attention, endear (Knobel \& Lankshear, 2007), and potentially establish a carnivalesque
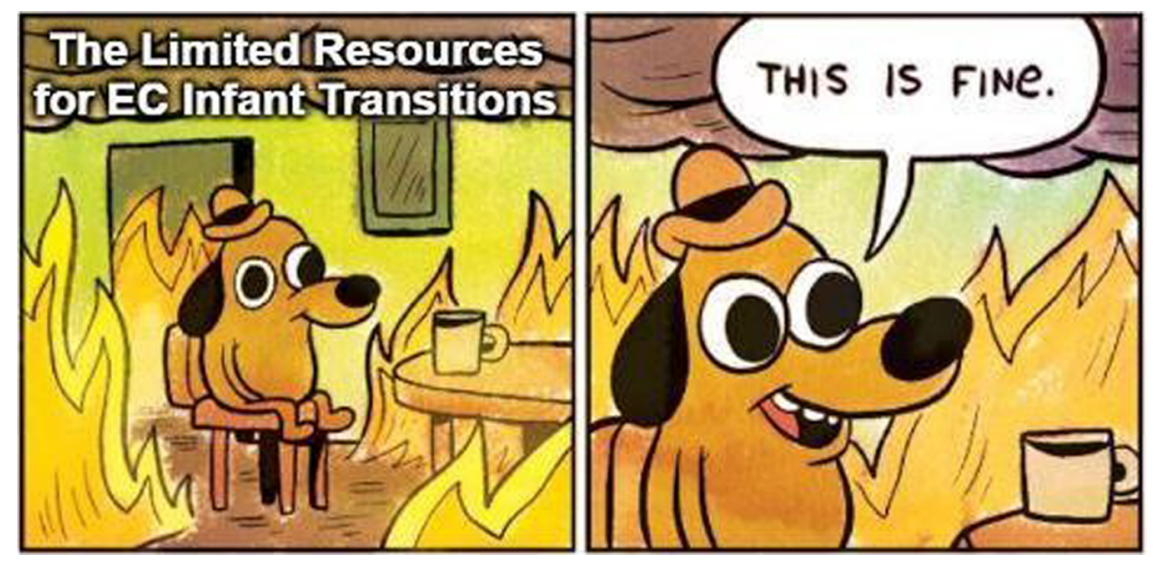

FIGURE 1 This is Fine meme 
"feast of becoming, change and renewal" (Bakhtin, 1984, p. 10) toward the reality of infant transitions in ECEC, based on our research.

The intricacies of each meme's form plus content further equated to our strategic orientation. The This is Fine meme shows an anthropomorphic dog, from The Gun Show series illustrated by K. C. Green, assuring himself everything is fine despite sitting in an alight room, often used as a reaction image that conveys self-denial or acceptance at a hopeless situation (Know Your Meme, 2021a). Our strategic orientation with this meme was to express acceptance or perhaps self-denial at the hopeless situation of the limited available resources for infant transitions. The emotional extremes that can be experienced for infants, families and teachers during these transitions (White et al., 2020) is reflective of the flames. Teachers' and families' available support in dealing with this intensity is mirrored by the non-reactive dog.

\section{I have enough information for early childhood infant transitions}

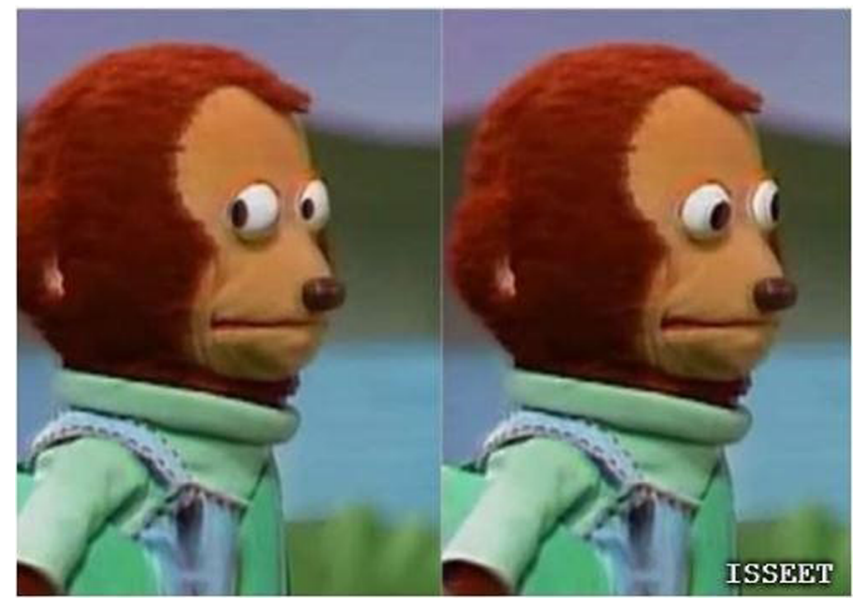

FIGURE 2 Monkey Puppet meme

The Monkey Puppet is another reaction meme to express an awkward look, originating from the Japanese children's television show Ōkiku Naru Ko and photoshopped to create two juxtapositioned images (Know Your Meme, 2021b). The form of the Monkey Puppet meme, thus, shows a puppet that 
has seen or learnt something that is awkward or humorously uncomfortable to be known. By adding the ironic content "I have enough information for early childhood infant transitions" we attempted to highlight, through carnivalesque humour, the lack of teacher supports for infant transitions. Our strategic orientation in doing so was to draw attention to and remedy this resource deficit.

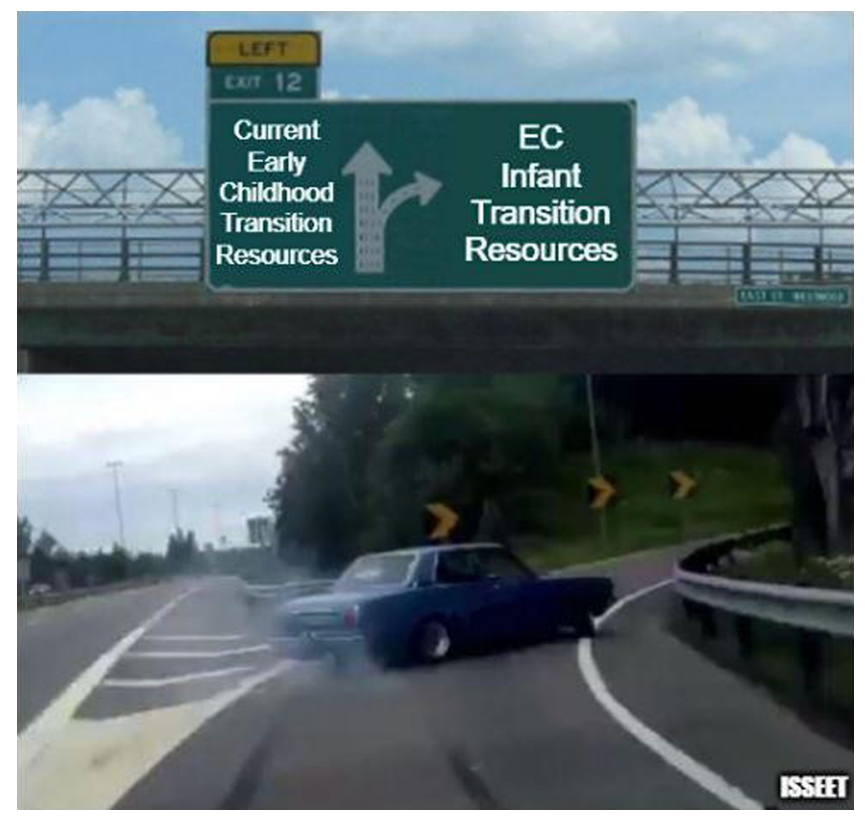

FIGURE 3 Left Exit meme

The final meme form, Left Exit commonly conveys a photo shopped highway sign, originating from a YouTube video titled "How to exit freeway like a boss", that includes a car veering away from something the creator disapproves of by careening toward a preferable thing (Know Your Meme, 2021c). Co-opting this for infant transitions, we altered the veering away from the current transition resources, that are predominantly for ECEC-to-primary-school-transitions, and speeding toward, and hopefully linkbaiting, our infant transition resources that recommend practices based on the social and emotional wellbeing of infants. In phase two of the study, we sought end-user feedback on the memes through anonymous surveys and this data raised a number of issues that we will discuss in the second half of this article. 
With ethics approval, we sought anonymous end-user feedback via Qualitrics survey links. These were sent and responded via emails to 5,000 ECEC centres in New South Wales (NSW), Australia based on publicly listed information. NSW was selected as COVID-19 led to research restrictions in other states at this time. The email requested that centre managers provide feedback and then pass on the survey to teachers and families for their input. The resource was embedded in the survey, which identify respondents' role and age bracket; then, how informative and visually appealing the resource was, and whether they would recommend them to teachers and families. Alongside the memes, we included one infographic and two short video clips, one intended to support families transitioning an infant and one for ECEC infant teachers.

The meme surveys received only one percent of feedback of those sent the link, with 59 responses to the This is Fine Meme and 36 for the other two memes in this article. The low response rate is likely impacted by the extraordinary pressure of CoviD-19 events, as well as the unsolicited emails. Centre managers and directors comprised 65 per cent of all respondents, ECEC educator/teachers 24 per cent, others (frequently researchers) made 10 per cent and families 2 per cent. We conducted a content analysis on the survey feedback by grouping common phrases or attitudes, then analysing for Bakhtinian genre as meaning (Hsieh \& Shannon, 2005).

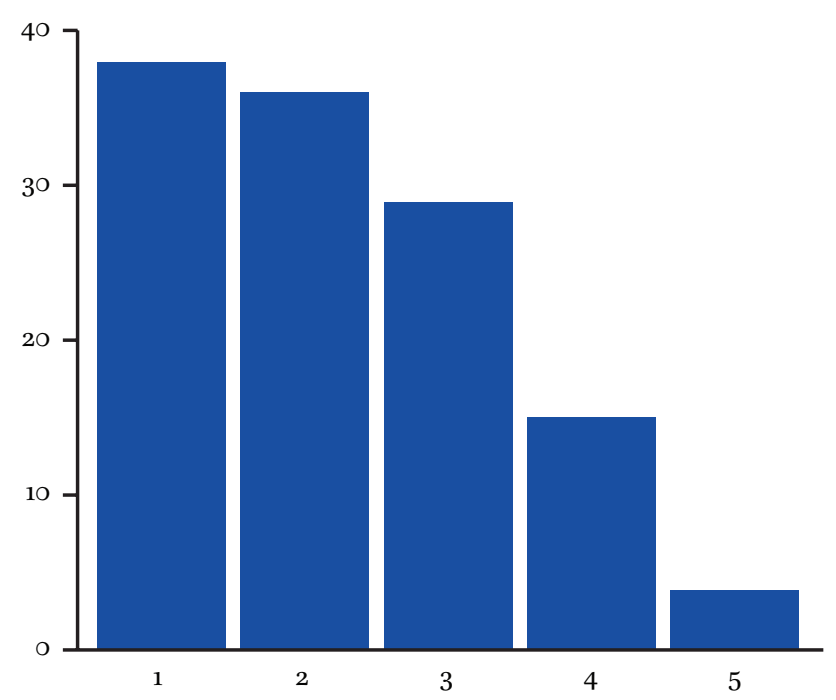

FIGURE 4 Meme appeal graph (1 - not appealing, 5 - very appealing) 
A fuller discussion of feedback across all the resources that were generated and discussed in the survey is beyond the scope of this article. Suffice to say that, whilst the infographic and short video clips received positive and constructive feedback for improvement, the memes did not. One example is a feedback statement that simply and vehemently stated: "Don't use a meme!". Figure 4 summarises these self-identified attitudes; the vertical axis shows the quantity of respondents, and the horizontal axis how appealing memes were to the respondent in this context ( 1 being the least and 5 the most appealing).

Considering the graphed responses, it is notable that our strategic orientation correlated to an intended audience of ECEC teachers predominantly aged 20-34. A group understood to be 'digital natives' who are known to routinely engage with memes and various digital platforms (Laineste \& Voolaid, 2017). However, this age-group made up only 24 per cent of survey respondents. At 65 per cent of respondents, ECEC centre managers aged 41 and above are the dominant group represented by the data. Whilst we do not presume to know the digital literacy and comfort levels of this group of participants, we contemplate how their strategic orientation may differ from the intended audience. In doing so we acknowledge that the intended primary end-user was not well-captured by the data. There is value, however, in the broad insight we have gained into the strategic orientation enshrined in these respondents' genre, and the ways that the form of memes may be utilised for early childhood and education research translation.

The qualitative responses provide more insight into the strategic orientation of the respondents' genre, revealing why they considered the memes unappealing. Breaking down differing themes in these genres highlights strategic orientations that are concerned with the unprofessionalism of a meme's form, and their usefulness as content messaging for the sector (see Table 1).

Regarding concerns about the usefulness of the memes content, we note that the survey instrument did not contextualise the memes for respondents or outline their intended usage as 'linkbait' (McGrath, 2018). A significant aspect of our strategic orientation, linkbait to support, was therefore not apparent within the received meme genre for the respondents. We acknowledge this as a limitation and focus the discussion hereafter on concerns around professionalism and the profession. Within this genre, the qualitative comments provide further insight into the respondents' strategic orientation, as follows (italics for emphasis). 
TABLE 1 Genre thematic analysis of qualitative survey responses

Genre theme

Number of times mentioned

(per survey)

Unprofessional

13

Not relevant

11

Unhelpful/uninformative

6

Negative

6

Unappealing/uninteresting

4

Derogatory to educators/sector

3

Inappropriate for children

This is Fine meme:

- Not something I would be sharing with parents, actually seems a bit derogative to the hard work and commitment made by educators every day (3)

- This meme does nothing for the profession of early childhood care and education (4)

- Seems pretty unprofessional and isn't really sending a great message to families (5)

Puppet Monkey meme:

- Why are you trying to use memes that are making parents and educators look so unprepared and unprofessional? (1)

- I would not use it as I feel it makes a joke of a serious subject (2)

Left Exit meme:

- Unprofessional and portraying the industry in a bad light (2)

The qualitative responses above highlight a strategic orientation that found the form and content of the memes offensive to the sector's professionalism, rather than a carnivalesque bonfire that could spark renewal. Wiggin's (2019) point, that the humour in memes tends to work by centring critique or satire on a certain target, becomes important in this context (p. 112). Our memes target the lack of support and resources available to the sector. However, our strategic orientation of carnivalesque humour that sought to reinvigorate infant transitions resources was 'lost in translation'. Unfortunately, our strategic orientation was 'lost in translation'. Instead of a renewing spark, the meme genre appeared to be interpreted as a critique that targeted the profession, understandably perceived as inappropriate. 
The responses highlight the subjectivity of humour and how hard is is to understand one another's genre within this online form, particularly internet meme humour (Chiaro, 2017). In personal exchanges, individuals can gauge responses, repour and timing, whereas with internet humour, "as we do not really know our audience... Humour may indeed hurt the feelings of others when it wrongly estimates their comfort zone" (Chiaro, 2017, p. 123). This notion of a 'comfort zone' is of interest to us, as meme humour can bring groups together through shared social phenomena, transcending boundaries like language and place (Chiaro, 2017). However, that success relies on a shared "cultural memory" (p. 26) through which strategic orientations of understanding and interpretations can be mediated (Laineste \& Voolaid, 2017). Although we had assumed the lack of infant transition resources to be a part of ECEC audiences' shared experience, or 'cultural memory,' the data suggest that the opposite may have resulted.

Contemplating the respondents' genre in this feedback, we also reflect on the time these surveys were sent out, CoviD-19. In Australia, early childhood services were encouraged to stay open through the federal government's free early childhood package. This framed ECEC as an economic stimulus keeping the economy afloat by allowing parents to return to work (Westbrook et al., in press). When considering these coordinates, it may be that the ECEC workforce feels the need to affirm its professionalism, one which surpasses a holding space for children so parents can work. Although care is an essential aspect of ECEC, the sector also offers professional knowledge and fine-tuned curriculum decisions that support children's developmental wellbeing (Essa \& Burnham, 2019). Supporting memes in the current climate could be unfavorably tensioned by this genre's untraditional and satirical content as a sector output. Therefore, the respondents' strategic orientation of unprofessionalism may be directly linked to the struggles of the sector. Whereby memes' untraditional genre could pose legitimacy concerns for ECEC professionals who have to consistently seek recognition for their works merit beyond a care service (Westbrook et al., in press).

To remediate these issues, we could provide context around the memes when they are encountered, creating that shared cultural memory to better support the humour in the messages. For example, we might use headings, questions, a brief introduction, or statistics to outline the problem and signal our resources as a potential site of assistance. This contextual information may also support audiences with primary languages other than English, who may interpret the subtle humour and nuances of memes differently than native speakers (Chiaro, 2017); this is fitting for the early childhood 
workforce in Australia which is culturally and linguistically diverse (Social Research Centre, 2017).

Last, we contend that the accountability culture pervading neoliberal, Australian early childhood policy needs to be considered as a time and space in the context of these responses. Neoliberal accountability culture situates fault or blame at an individual or managerial level and does not encourage individuals to critique the complex systems that contextualise challenges (Duhn, 2010). As Ball (2012) explains, neoliberal education policies work to professionalise education systems through regimes of standardisation, accountability, and scrutiny. Since nationalised quality standardised assessments and ratings were introduced in Australia in 1994, and strengthened in 2009, the performance pressures felt by the early childhood workforce have increased (Kilderry, 2015; Thorpe, 2021; Wood, 2014). Alongside this the challenges of working conditions have grown, such as high staff turnover, feelings of being undervalued and low wages (Jackson, 2021).

Based on the qualitative responses, the dominant respondents' strategic orientation reveals a concern of memes as a problem idea, often considered a negative portrayal of the sector and its workforce. Within the aforementioned culture, we are sympathetic to these concerns but argue that the discomfort has a place in research translation that seeks to impact professional practices. A recent study by Nolan and Molla (2018) highlighted that discomfort is a critical aspect of teacher reflection, triggering change and growth. Whilst the ethics of meme culture are underdeveloped (McGrath, 2018), internet trolls are a useful example of how meme-agery is deployed to intentionally and persistently inflict hurt (Nycyk, 2018). However, other memes (such as ours) differ in their attempt to challenge the status quo, critically engaging with 'norms', at times creating levels of agitation or annoyance (Kearney, 2019). We question whether research translation needs to avoid creating feelings of discomfort for the imagined audience: Can we ever assume comfort for all? Is it the responsibility of research translation to make audiences comfortable? This is an ethical and moral dilemma around which more thought and research is needed. Intensifying this issue are increased foci on academic's metric 'impacts' such as views, shares and comments (regardless of their quality). Nolan and Molla (2018) contend that professional learning requires support and facilitation, a goal our visual resources sought. However, with the memes causing offence, our intent of linkbait to this support is unlikely to occur, suggesting that a new approach is required. 


\subsection{Co-Constructing Meanings}

A secondary finding from the survey responses was that some audiences, albeit the minority, tended to interpret the memes literally. For example, the feedback for the This is Fine meme (a dog stationary among a burning room) and the drifting car in the Left Exit meme raised safety concerns:

\section{This is Fine:}

Very unethical, no hot substance is allowed near child/children (1) it doesn't promote safety (2)

\section{Left Exit:}

This is the wrong sense given to the children (1)

Why is the car driving recklessly? (2)

These comments may reflect an end-user genre that is not familiar with memes and/or has not understood that it is symbolic rather than literal strategic orientation intended for adults. Memes have only come to prominence as a digital communication genre within the last two decades and, as they are predominantly an internet communication genre, require a level of digital literacy (Laineste \& Voolaid, 2017). If the essential form of this genre is not understood, then the intended strategic orientation cannot be engaged with either. The responses tell us that we cannot assume digital and meme literacy across all our intended audience end-users, making a variety of genres necessary for broad attempts at research translation like ours. Particularly as Wiggins (2019) points out, memes are a unique genre of communication insofar as the form plus content being communicated do not belong to the author, nor are they static. Instead, memes and their strategic orientations are created over time through audience interaction and layering such as use (posts) and reuse (co-opting memes). It is possible therefore, that an intended message is lost or changed in those processes, as ours has been in the responses above.

Although more critical, research related inquiry is needed, it stands to reason that informal online genres could appeal in different ways to different audiences. Memes could - with careful consideration and sector engagement - be a valuable research translation genre. If they accompany a multi-modal suite of resources, they could potentially reach and support a wider audience, which may be harder to reach through traditional means. For these reasons, we continue to suggest memes as rich research translation tools.

Persisting with the possibilities of memes as a genre, we continue this conversation by offering two additional ones (see Figures 5 and 6 ). Although these have not undergone sector feedback, we present them against the gaps and 
needs mentioned above for infant transition resources, something we originally failed to do. Furthermore, we have selected Baby Yoda, who has become a recent meme sensation from The Mandalorian television series, described in pop-culture references, outside of officialdom, as "shockingly relatable" (Alex, 2021, para. 3). With our strategic orientation of teacher engagement, the form and content of these memes intend to offer supportive pedagogical provocations that we hope will be relatable. Acknowledging the sector's professionalism concerns, we have not returned to a satirical emphasis on the lack of available resources, rather oriented by a jovial carnivalesque attempt at ISSEET-informed renewal of practices. By centring these memes on "what works" strategies rather than linkbait, we attempt to support quality infant transitions that still have some levels of discomfort through the "what not to do" imagery of teacher distraction (Figure 5) and rigid routines (Figure 6). Our strategic orientation in doing so is impactful provocations that beget change, as Nolan and Molla (2018) suggest this level of provocative discomfort is central for professional learning. .
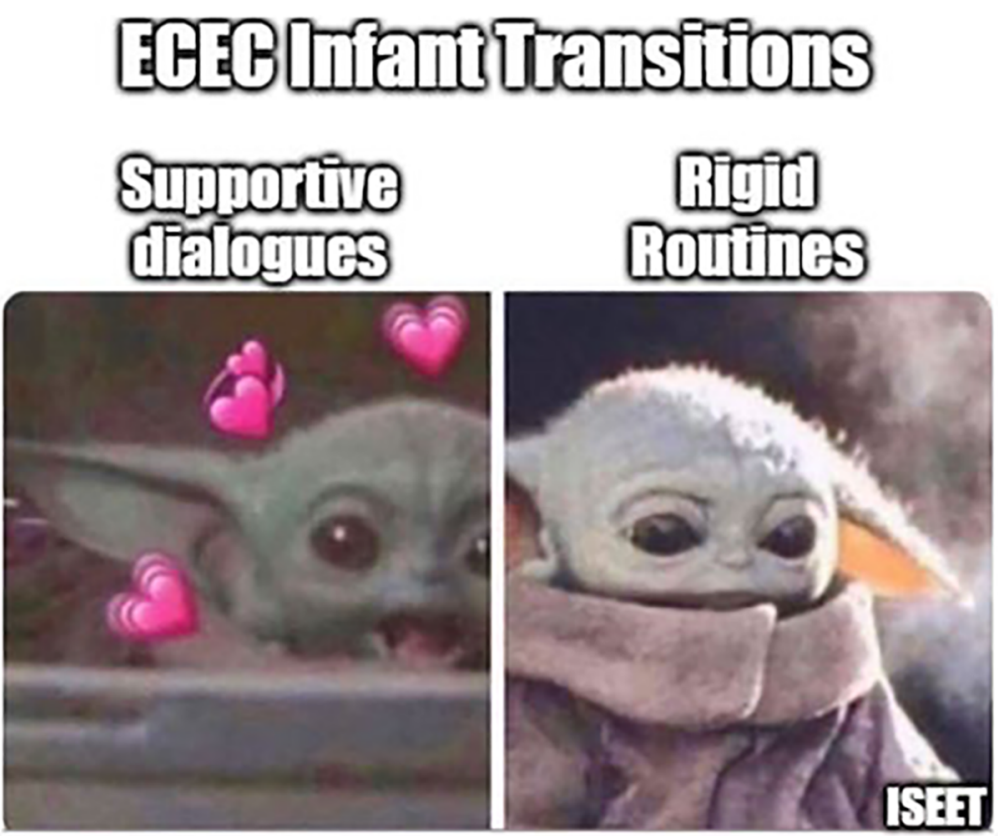

Figure 5 Connection Over Distraction meme 


\section{EBE:Bnfant Transitions}
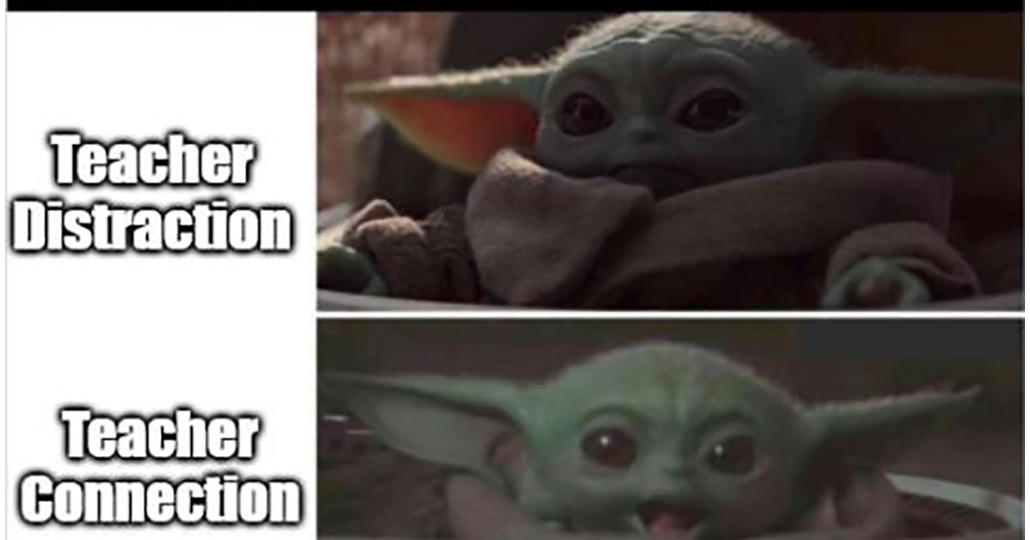

FIGURE 6 Support Over Routines meme

Thinking Forward (Critically) with Memes in Research Translation in Education

This article's findings have contributed to understandings about how meme resources can be used to translate research for early childhood audiences. Survey feedback from end-user audiences' strategic orientation revealed that our memes were seen as unprofessional, with potentially harmful messages and imagery content. This is a far stretch from our intended orientation of a carnivalesque spark of laughter for infant transitions "so that new bearings could be taken" (Bakhtin, 1984, p. 273). It may be that ECEC's ongoing, and CoviD-19 exacerbated, struggles for legitimacy (White et al., in press) complicate the use of memes as an untraditional genre. Despite this negative feedback, we remain optimistic. We have noted various ways that we can improve the suitability of memes as a provocation for ISSEET's short term, and also highlighted areas for future exploration in the longer term. First, careful thought is needed by researchers in regard to the intended audience. They should consider the shared cultural memory that is being tapped into, and the potential reception as well as interpretation of the genre's strategic orientation. Second, there is need to acknowledge, and ethically contemplate, that the journey into new types of visual genre for research transition will not necessarily please or suit all audiences. 
Whilst the use of social media has been popularised as a means of spreading messages and building/sharing community (Conroy et al., 2012), further work in is needed around the opportunities memes offer for research translation. We take up this work through our additional Baby Yoda memes, inviting lively debates about these renewed infant transition provocations. In conclusion, although there are current tensions surrounding memes, we continue to lament that they offer new possibilities for research translation, especially given the future audience.

\section{Acknowledgements}

The authors gratefully acknowledge RMIT University for funding this research project via the Enabling Capabilities Project (ECP) fund (RMIT University, 2020). We also acknowledge and thank the international ISSEET team members - Helen Marwick (Scotland), Katia Armorim (Brazil), Niina Rutanen (Finland) and Laura Herold (USA) - for their assistance throughout this project. We are also and especially grateful to our Australian ECEC sector steering committee who provided advice concerning both the message and the resources; and to the ECEC community members across NSW who provided such illuminating feedback.

\section{References}

Adams, E., \& Parlakian, R. (2010). Movin' on: Supportive transitions for infants and toddlers. Yc Young Children, 65(3), 54-55.

Alex, B. (2021). Baby Yoda memes that are way too relatable. https://www. workandmoney.com/s/brilliant-baby-yoda-memes-c87d592a392e4811.

Bakhtin, M. (1984). Rabelais and his world (1st ed.). Indiana University Press.

Bakhtin, M. M., Holquist, M., \& Emerson, C. (1986). Speech genres and other late essays (1st ed). University of Texas Press.

Ball, S. J. (2012). Globaleducation inc: New policynetworks and the neo-liberal imaginary. Routledge.

Beben, M., \& McCormilla, L. (2012). Plan effective transitions for children in education and care services. Western Australia: Child Australia. https://www.acecqa.gov.au/ sites/default/files/2021-01/PlanEffectiveTransitionsForChildren.PDF.

Benaim, M. (2018). From symbolic values to symbolic innovation: Internet-memes and innovation. Research Policy, 47(5), 901-910. https://www.doi.org/10.1016/j. respol.2018.02.014. 
Brunton, F. (2018). Spam. In N. Brügger \& I. Milligan (Eds.). The sage handbook of web history (pp 564-577). Sage Publishers.

Buchanan, R., \& Newman, S. (2019, Dec 1-5). 'Hey Policy Makers! Leave Jeannette alone!' [Paper presentation]. AARE Conference QUT, Kelvin Grove.

Bupa. (2017). Child development research-first 1000 days. New research: The first thousand days evidence paper. Bupa. https://media.bupa.com.au/ research-unborn-babies-predict-the-world-they-will-live-in/.

Burmark, L. (2002). Visual literacy: Learn to see, see to learn. Association for Supervision and Curriculum Development.

Cherney, A., Povey, J., Head, B., Boreham, P., \& Ferguson, M. (2012). What influences the utilisation of educational research by policy-makers and practitioners?: The perspectives of academic educational researchers. International Journal of Educational Research, 56, 23-34. https://www.doi.org/10.1016/j.ijer.2012.08.001.

Chiaro, D. (2017). The language of jokes in the digital age: viral humour. Taylor \& Francis Group.

Conroy, M., Feezell, J. T., \& Guerrero, M. (2012). Facebook and political engagement: A study of online political group membership and offline political engagement. Computers in Human Behavior, 28(5), 1535-1546. https://www.doi.org/10.1016/j. chb.2012.03.012.

Dawkins, R. (2016). The selfish gene: 4oth anniversary edition. Oxford University Press.

Djamasbi, S., Siegel, M., \& Tullis, T. (2010). Generation Y, web design, and eye tracking. International Journal of Human-Computer Studies, 68(5), 307-323. https://www.doi. org/10.1016/j.ijhcs.2009.12.006.

Duhn, I. (2010). 'The centre is my business': Neo-liberal politics, privatisation and discourses of professionalism in New Zealand. Contemporary Issues in Early Childhood, 11(1), 49-6o. https://www.doi.org/10.2304/ciec.2010.11.1.49.

Essa, E. L., \& Burnham, M. M. (2019). Introduction to early childhood education. Sage Publications.

Gradovski, M., Janfaba, M., Janfaba, C., Redder, B., Westbrook, F., \& White, E. J. (2019). Dangerous images and dialogic responses [Panel Presentation]. AVP Conference: Ocular Becomings in Dangerous Times: The Politics of Seeing, Melbourne, Australia.

Hirschkorn, M., \& Geelan, D. (2008). Bridging the research-practice gap: research translation and/or research transformation. Alberta Journal of Educational Research, 54(1), 1. https://journalhosting.ucalgary.ca/index.php/ajer/article/view/55207.

Hsieh, H. F., \& Shannon, S. (2005). Three approaches to qualitative content analysis. Qualitative Health Research, 15, 1277-1288. https://www.doi. org/10.1177/1049732305276687.

Jackson, J. (2021). Early childhood educators are leaving in droves. Here are three ways to keep them, and attract more. The Conversation. https://www.theconversation. 
com/early-childhood-educators-are-leaving-in-droves-here-are-3-ways-to-keepthemand-attract-more-153187.

Johnson, E. (2019, March 24). The PewDiePipeline: How edgy humor leads to violence. YouTube. https://www.youtube.com/watch?v=pnmRYRRDbuw.

Kearney, R. (2019). Meme frameworks: A semiotic perspective on internet memes. Video Journal of Education and Pedagogy, 4(2), 82-89. https://www.doi. org/10.1163/23644583-00401013.

Kilderry, A. (2015). The intensification of performativity in early childhood education. Journal of Curriculum Studies, 47(5), 633-652. https://www.doi.org/10.1080/0022027 2.2015.1052850.

Knobel, M., \& Lankshear, C. (2007). Online memes, affinities, and cultural production. In M. Knobel \& C. Lankshear (Eds.), A New Literacies Sampler (Vol. 29, pp. 199-227). Peter Lang.

Know Your Meme. (2021a). This is fine. https://knowyourmeme.com/memes/this-is-fine.

Know Your Meme. (2021b). Awkward look monkey puppet. https://knowyourmeme. com/memes/awkward-look-monkey-puppet.

Know Your Meme. (2021c). Left exit 12 off ramp. https://knowyourmeme.com/memes/ left-exit-12-off-ramp.

Kulkarni, A. (2017). Internet meme and political discourse: A study on the impact of internet meme as a tool in communicating political satire. Social Science Research Network. https://www.doi.org/10.2139/ssrn.3501366.

Laineste, L., \& Voolaid, P. (2017). Laughing across borders: Intertextuality of internet memes. The European Journal of Humour Research, 4(4), 26-49. https://www.doi. org/10.7592/EJHR2016.4.4.laineste.

Levin, B. (2011). Mobilising research knowledge in education. London Review of Education, 9(1), 15-26. https://www.doi.org/10.1080/14748460.2011.550431.

Lindgaard, G., Dudek, C., Sen, D., Sumegi, L., \& Noonan, P. (2011). An exploration of relations between visual appeal, trustworthiness and perceived usability of homepages. ACM Transactions on Computer-Human Interaction, 18(1), 1-30. https:// www.doi.org/10.1145/1959022.1959023.

Mat Roni, S., Merga, M. K., \& Morris, J. E. (2020). Write up and research translation. In S. Mat Roni , M. K. Merga , \& J. E. Morris (Eds.), Conducting quantitative research in education (pp. 177-192). Springer. https://www.doi.org/10.1007/978-981-13-9132-3_9.

McGrath, J. (2018). Memes. In N. Brügger \& I. Milligan (Eds.). The sage handbook of web history (pp 505-520). Sage Publishers.

Miller, K. (2005). Simple transitions for infants and toddlers. Gryphon House Inc.

Moody-Ramirez, M., \& Church, A. B. (2019). Analysis of Facebook meme groups used during the 2016 us presidential election. Social Media + Society, 5(1). https://www. doi.org/10.1177/2056305118808799. 
Nagle, A. (2017). Kill all normies: Online culture wars from 4chan and Tumblr to Trump and the alt-right. John Hunt Publishing.

Nissenbaum, A., \& Shifman, L. (2015). Internet memes as contested cultural capital: The case of 4chan's /b/ board: New Media \& Society, 19(4), 483-501. https://www.doi. org/10.1177/14614448156o9313.

Nolan, A., \& Molla, T. (2018). Teacher professional learning in early childhood education: Insights from a mentoring program. Early Years, 8(3), 258-270

Nycyk, M. (2018). Trolls and trolling history: From subculture to mainstream practices. In N. Brügger \& I. Milligan (Eds). The sage handbook of web history (pp 577-591). Sage Publishers.

Peeters, J., \& Vandenbroeck, M. (2011). Childcare practitioners and the process of professionalization. In L. Miller \& C. Cable (Eds.), Professionalization, leadership and management in the early years (pp. 62-76). Sage Publications Ltd. https://www. doi.org/10.4135/9781446288795.n5.

Pink, S. (2020). Foreword. In E. J. White (Ed.), Seeing the world through children's eyes: Visual methodologies and approaches to research in the early years (p. IV-XII). Brill Sense.

RMIT University. (2021). First steps: Supporting quality transitions to early childhood settings in the first 1000 days. https:/www.rmit.edu.au/about/schools-colleges/ education/research/research-projects/first-steps.

Rutanen, N., Amorim, K. de S., Marwick, H., \& White, E.J. (2018). Tensions and challenges concerning ethics on video research with young children-Experiences from an international collaboration among seven countries. Video Journal of Education and Pedagogy, 3(1), 7. https://www.doi.org/10.1186/s4099o-018-oo19-X.

Schwartz, K., Cappella, E., Aber, J. L., Scott, M. A., Wolf, S., \& Behrman, J. R. (2019). Early childhood teachers' lives in context: Implications for professional development in under-resourced areas. American Journal of Community Psychology, 63(3-4), 270285. https://www.doi.org/10.1002/ajcp.12325.

Social Research Centre. (2017). 2016 Early childhood education and care national workforce census. Department of Education and Training.

Te Rūnanga Ngāi Tahu. (2018). Te aka matua. Te Rūnanga o Ngāi Tahu. https://ngaitahu. iwi.nz/education/te-aka-matua/.

Thorpe, K., Westwood, E., Jansen, E., Menner, R., Houen, S., \& Staton, S. (2021). Working towards the Australian national quality standard for ECEC: What do we know? Where should we be? The Australian Educational Researcher, 48, 227-247.

UNICEF. (2018). Early moments matter! https://www.unicef.org/moldova/en/ early-moments-matter.

Westbrook, F., Redder, B., \& White, E. J. (In press). A 'quint-essential(ised)' ECE workforce: Covidıg and the exploitation of labour. In L. Henderson , H. Ebrahim , \& 
K. Bussey (Eds.), Early Childhood Education and Care in a Global Pandemic: How the sector responded, spoke back and generated knowledge. Routledge.

White, E. J. (2009). Assessment in New Zealand early childhood education: A Bakhtinian analysis of toddler metaphoricity, [Doctoral Thesis]. Monash University. https:// monash.figshare.com/articles/Assessment_in_New_Zealand_early_childhood_ education_a_Bakhtinian_analysis_of_toddler_metaphoricity/4545991.

White, E. J. (2017). Video ethics and young children. Video Journal of Education and Pedagogy, 2(1), 2. https://www.doi.org/10.1186/s4099o-017-0012-9.

White, E. J., Rutanen, N., Marwick, H., Amorim, K. S., Karagiannidou, E., \& Herold, L. K. M. (2O2O). Expectations and emotions concerning infant transitions to ECEC: International dialogues with parents and teachers. European Early Childhood Education Research Journal, 28(3), 363-374. https://doi.org/10.1080/13502 93X.2020.1755495.

White E. J., Marwick, H., Amorim, K., Karagiannidou, E., and Herold, L. K. M. (In press). First transitions to early childhood education and care - culturally responsive approaches to the people, places, environments, and ideologies of earliest care encounters. Springer.

Wiggins, B. E. (2019). The discursive power of memes in digital culture: ideology, semiotics, and intertextuality. Taylor \& Francis Group.

Woods, E. (2014). The play-pedagogy interface in contemporary debates. In E. Brooker, M. Blaise, \& S. Edwards (Eds.), Sage handbook of play and learning in early childhood (pp. 145-156). Sage Publications Ltd.

Yus, F. (2018). Identity-related issues in meme communication. Internet Pragmatics, 1(1), 113-133. https://www.doi.org/10.1075/ip.oooo6.yus. 